\title{
Papers
}

\section{Factors predisposing to perinatal death related to uterine rupture during attempted vaginal birth after caesarean section: retrospective cohort study}

\author{
Gordon C S Smith, Jill P Pell, Dharmintra Pasupathy, Richard Dobbie
}

\begin{abstract}
Objective To determine the factors associated with an increased risk of perinatal death related to uterine rupture during attempted vaginal birth after caesarean section. Design Population based retrospective cohort study. Setting Data from the linked Scottish Morbidity Record and Stillbirth and Infant Death Survey of births in Scotland, 1985-98.

Participants All women with one previous caesarean delivery who gave birth to a singleton infant at term by a means other than planned repeat caesarean section $(\mathrm{n}=35854)$.

Main outcome measures All intrapartum uterine rupture and uterine rupture resulting in perinatal death (that is, death of the fetus or neonate).

Results The overall proportion of vaginal births was $74.2 \%$ and of uterine rupture was $0.35 \%$. The risk of intrapartum uterine rupture was higher among women who had not previously given birth vaginally (adjusted odds ratio $2.5,95 \%$ confidence interval 1.6 to $3.9, \mathrm{P}<0.001$ ) and those whose labour was induced with prostaglandin $(2.9,2.0$ to $4.3, \mathrm{P}<0.001)$. Both factors were also associated with an increased risk of perinatal death due to uterine rupture. Delivery in a hospital with $<3000$ births a year did not increase the overall risk of uterine rupture $(1.1,0.8$ to $1.5, \mathrm{P}=0.67)$. However, the risk of perinatal death due to uterine rupture was significantly higher in hospitals with $<3000$ births a year (one per 1300 births) than in hospitals with $\geq 3000$ births a year (one per $4700 ; 3.4,1.0$ to 14.3 , $\mathrm{P}=0.04$ ).

Conclusion Women who have not previously given birth vaginally and those whose labour is induced with prostaglandin are at increased risk of uterine rupture when attempting vaginal birth after caesarean section. The risk of consequent death of the infant is higher in units with lower annual numbers of births.
\end{abstract}

\section{Introduction}

Uterine rupture during attempted vaginal birth after a previous caesarean section is a rare event that affects about one in 200 women, ${ }^{1}$ and consequent death of the infant is even rarer, affecting about one per $2000 .^{2}$ Analysis of the factors determining perinatal death due to uterine rupture therefore requires data from large numbers of women. Most large scale databases of births lack detailed information on the cause of perinatal death and the obstetric characteristics of the population. Consequently, we know of no reports of the risk factors for perinatal death due to uterine rupture during attempted vaginal birth after previous caesarean section. We linked national registries of pregnancy discharge data and perinatal death to determine the factors associated with this event.

\section{Methods}

The inclusion criteria for the study were that a woman had previously had one caesarean section and was delivered in her current pregnancy by a means other than planned caesarean section. We excluded women with more than one previous caesarean, those with multiple gestations, those delivering before 37 weeks' gestation, and those delivering beyond 43 weeks' gestation. We also excluded cases in which the infant died from causes other than intrapartum uterine rupture.

Data sources-The Scottish Morbidity Record (SMR2) collects information on clinical and demographic characteristics and outcomes for all patients discharged from Scottish maternity hospitals. The register is subjected to regular quality assurance checks and has been $>99 \%$ complete since the late 1970 s. $^{3}$ The register collects both specific obstetric data and up to six ICD-9 (international classification of diseases, ninth revision) or ICD-10 (10th revision) diagnostic codes relating to the admission. In 1996-7 a quality assurance analysis comparing 1414 records with the clinical notes showed that the register was free from significant errors in $>98 \%$ of records in all the specific fields used in the present analysis. Exceptions were postcode (94.0\%), height (96.2\%), estimated gestation (94.4\%), and method of induction of labour (93.6\%). The previous caesarean section field was $99.7 \%$ accurate. ICD diagnostic codes were found to be $80-90 \%$ accurate for the first four diagnoses and $70-80 \%$ accurate for the remainder (Jim Chalmers, personal communication). SMR2 records were linked to records from the Scottish Stillbirth and Infant Death Survey. This national register routinely classifies all perinatal deaths in Scotland. Coding of the cause of death is performed by a single medically qualified individual, and the survey is described in detail elsewhere. ${ }^{4}$

Definitions-We defined trial of labour as a singleton delivery at term by a means other than planned caesarean section in women with only one previous caesarean delivery. The definition of perinatal death due to uterine rupture was that the obstetric cause of death was coded as "mechanical" under the modified Wigglesworth classification ${ }^{5}$ and that the ICD-9 diagnostic code for intrapartum uterine rupture (665.1) was listed under the specific diagnoses. Intrapartum uterine ruptures that did not result in perinatal death were identified with ICD-9 and ICD-10 diagnostic codes 665.1 and $\mathrm{O} 711$, respectively, from the 
diagnostic fields in the SMR2 record related to hospital discharge after delivery. Hospital throughput was defined as the total number of births recorded in the SMR2 database for the given hospital over the given year. Hospital throughput was categorised into above or below the median (3000 births). Other maternal characteristics were defined as previously described. ${ }^{2}$

Statistical analyses-We summarised continuous variables with medians and interquartile ranges and used the Mann-Whitney U test for comparisons between groups and Fisher's exact test for univariate comparisons of dichotomous data. $\mathrm{P}$ values for all hypothesis tests were two sided. Multivariate analysis was performed using logistic regression analysis. The significance of interaction terms was assessed with the likelihood ratio test. The goodness of fit of models was assessed with the Hosmer and Lemeshow test based on tenths of probability. ${ }^{6}$ Because of the rarity of the event we used exact logistic regression to model the risk of perinatal death due to uterine rupture. ${ }^{7}$ When we treated annual number of births as a continuous variable in the exact model, we rounded it to the nearest 50 to make the model computationally feasible. All statistical analyses were performed with the Stata software package version 8.2 (StataCorp, College Station, TX), except for exact logistic regression, which was performed with LogXact version 5.0 (Cytel Software Corporation, Cambridge, MA).

\section{Results}

There were 871283 SMR2 birth records for Scotland for 198598. In total 39729 (4.6\%) women had had one previous caesarean delivery and were delivered by a means other than planned caesarean section. There were 452 (1.1\%) multiple births, 3462 $(8.7 \%)$ births outside the range of $37-43$ weeks' gestation, and $543(1.4 \%)$ perinatal deaths due to causes other than intrapartum uterine rupture. We excluded a further $32(<0.1 \%)$ records because the women were documented as being primigravid, despite having had a previous caesarean delivery. We therefore excluded $3875(9.8 \%)$ records (some cases were excluded in more than one category), leaving a study group of 35 854. We compared the demographic and obstetric characteristics of the study group according to whether there was a perinatal death due to uterine rupture (table 1).

There was no association between the annual number of deliveries and the risk of emergency caesarean delivery (odds ratio $1.00,95 \%$ confidence interval 0.98 to $1.01, \mathrm{P}=0.58$ ) or uterine rupture overall $(0.98,0.86$ to $1.11, \mathrm{P}=0.70)$, but there was a significant negative association with the risk of perinatal death due to uterine rupture $(0.68,0.46$ to $0.99, \mathrm{P}=0.04)$ (figure).

On univariate analysis, with the 35854 women who attempted vaginal birth as the denominator, the risk of uterine rupture was higher in women who had not previously given birth vaginally and in women who had been induced with prostaglandin but not with other methods of induction (table 2). Though delivery in a hospital with $<3000$ births a year was not associated with the risk of uterine rupture overall, the other associations remained highly significant in multivariate analysis and the point estimates were similar (table 3). There were enough uterine ruptures for us to test the goodness of fit of the model and to examine interactions between the variables. The goodness of fit was adequate $(\mathrm{P}>0.05)$, and there were no significant first order interactions between any of the variables with each other or with the year of birth.

The risk of perinatal death due to uterine rupture was also higher in women who had not previously given birth vaginally and in women who had been induced with prostaglandins but
Table 1 Maternal demographic and obstetric characteristics in relation to perinatal death due to uterine rupture. Figures are numbers (percentages) unless stated otherwise

\begin{tabular}{|c|c|c|c|}
\hline & $\begin{array}{l}\text { No perinatal death* } \\
(\mathrm{n}=35 \text { 837) }\end{array}$ & Perinatal death $(n=17)$ & $P$ valuet \\
\hline $\begin{array}{l}\begin{array}{l}\text { Median (IQR) age } \\
\text { (years) }\end{array} \\
\text { (a) }\end{array}$ & $29(26-32)$ & $27(25-31)$ & 0.61 \\
\hline $\begin{array}{l}\text { Median (IQR) height } \\
\quad(\mathrm{cm})\end{array}$ & $161(157-165)$ & $158(153-163)$ & 0.13 \\
\hline Height data missing & $2927(8.2)$ & $2(11.8)$ & 0.64 \\
\hline \multicolumn{4}{|l|}{ Marital status: } \\
\hline Married & $28548(79.7)$ & $15(88.2)$ & \multirow[t]{2}{*}{$>0.9$} \\
\hline Other & $7289(20.3)$ & $2(17.8)$ & \\
\hline \multicolumn{4}{|c|}{ Fifth of deprivation distribution: } \\
\hline 1 (least deprived) & $6418(17.9)$ & $2(11.8)$ & \multirow[t]{6}{*}{0.82} \\
\hline 2 & $6731(18.8)$ & $3(17.6)$ & \\
\hline 3 & 6854 (19.1) & $2(11.8)$ & \\
\hline 4 & $7219(20.1)$ & $5(29.4)$ & \\
\hline 5 (most deprived) & $8182(22.8)$ & $5(29.4)$ & \\
\hline Missing & $433(1.2)$ & $0(0.0)$ & \\
\hline \multicolumn{4}{|c|}{ No of previous vaginal births } \\
\hline None & $23176(64.7)$ & $15(88.2)$ & \multirow[t]{2}{*}{0.04} \\
\hline One or more & $12661(35.3)$ & $2(11.8)$ & \\
\hline \multicolumn{4}{|c|}{ No of spontaneous abortions: } \\
\hline None & $27574(76.9)$ & $12(70.6)$ & \multirow[t]{2}{*}{0.57} \\
\hline$\geq 1$ & $8263(23.1)$ & $5(29.4)$ & \\
\hline \multicolumn{4}{|l|}{ No of therapeutic abortions: } \\
\hline None & $32202(89.9)$ & $16(94.1)$ & \multirow[t]{2}{*}{$>0.9$} \\
\hline$\geq 1$ & $3635(10.1)$ & $1(5.9)$ & \\
\hline \multicolumn{4}{|l|}{ Year of delivery: } \\
\hline$<1992$ & $17539(48.9)$ & $9(52.9)$ & \multirow[t]{2}{*}{0.74} \\
\hline$\geq 1992$ & $18298(51.1)$ & $8(47.1)$ & \\
\hline $\begin{array}{l}\text { Median (IQR) No of } \\
\text { deliveries in hospital } \\
\text { in given year }\end{array}$ & 3120 (1794-4 129) & 2154 (1681-2718) & 0.05 \\
\hline \multicolumn{4}{|l|}{ Sex of infant: } \\
\hline Female & $17594(49.1)$ & $11(64.7)$ & \multirow[t]{2}{*}{0.23} \\
\hline Male & $18243(50.9)$ & $6(35.3)$ & \\
\hline $\begin{array}{l}\text { Median (IQR) weight (g) } \\
\text { of infant }\end{array}$ & 3445 (3118-3780) & $3242(3150-3840)$ & 0.76 \\
\hline
\end{tabular}

\section{IQR=interquartile range.}

*Includes 35730 women who did not have uterine rupture documented and 107 women who had uterine rupture documented but it did not result in stillbirth or neonatal death of infant. †Mann-Whitney U test or Fisher's exact test, as appropriate.

not with other methods of induction (table 2). However, in addition, delivery in a hospital with $<3000$ births a year was associated with a significantly increased risk of perinatal death due to uterine rupture. The risk of perinatal death was about one in 1300 in hospitals with $<3000$ births a year and one in 4700 in hospitals with $\geq 3000$ births a year. Because of the small number of deaths caused by uterine rupture, significance was generally attenuated in multivariate analysis (table 3). However, the point estimates were similar to those from the univariate analysis, indicating that the associations seen in univariate analysis were not due to confounding by the factors included in the model. There were too few events for us to assess goodness of fit or first order interactions.

Among the 124 cases of uterine rupture, there were 17 (13.7\%) intrapartum stillbirths or neonatal deaths. There were 63 uterine ruptures in hospitals delivering $<3000$ women per year and $13(20.6 \%)$ resulted in perinatal death. In hospitals delivering $\geq 3000$ women a year there were 61 uterine ruptures and four $(6.6 \%)$ resulted in perinatal death $(\mathrm{P}=0.03)$. Among women with uterine rupture, the relative risk of perinatal death in a hospital with $<3000$ births a year was about threefold (table 4). 

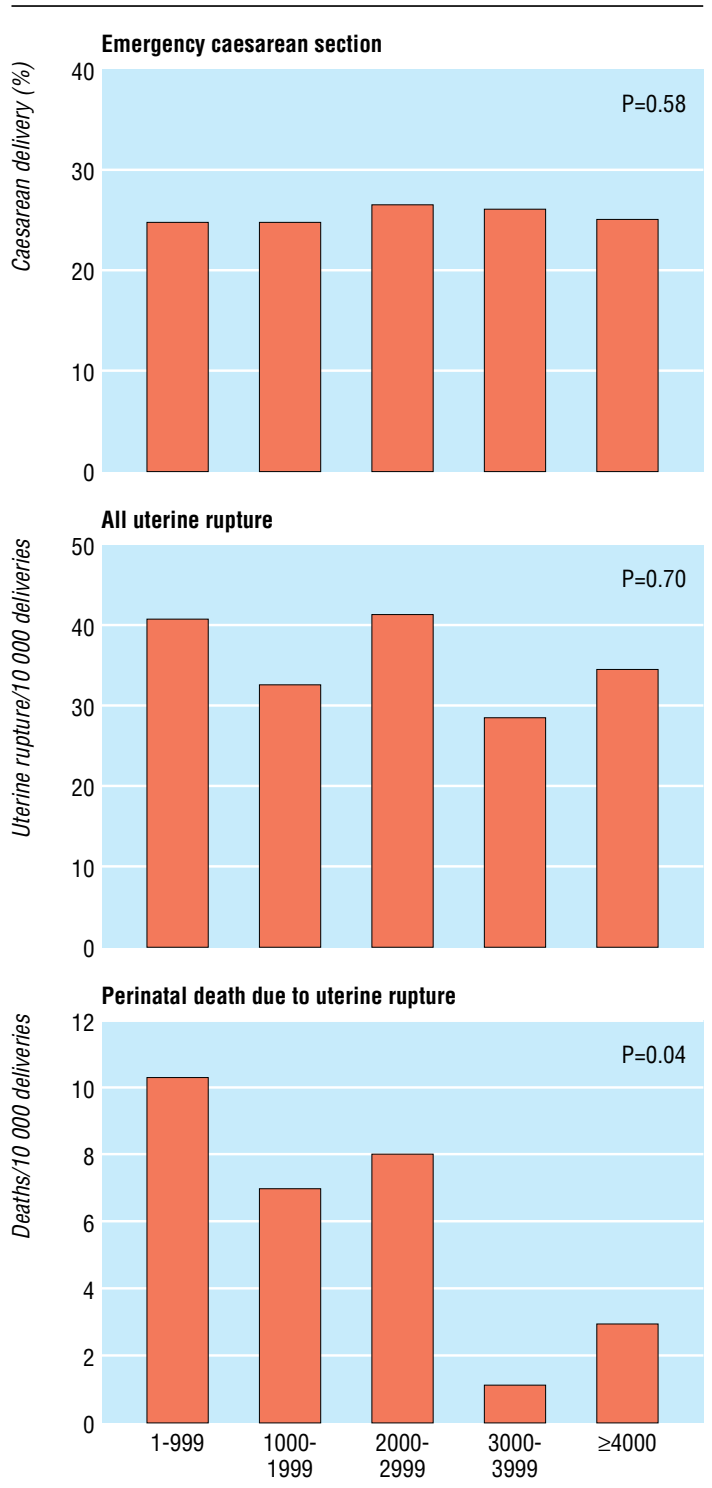

Deliveries per year

Proportions of emergency caesarean section, all uterine rupture, and perinatal death due to uterine rupture, in relation to size of hospital

When we confined the analysis to births $\geq 40$ weeks' gestation, the risk of uterine rupture was significantly associated with no previous vaginal birth (odds ratio 2.0, 95\% confidence interval 1.2 to $3.4, \mathrm{P}=0.009$ ) and induction of labour with pros- taglandin $(2.2,1.4$ to $3.5, \mathrm{P}=0.001)$. Formal tests of interaction between each of these variables and gestation $\geq 40$ weeks showed that the strength of the associations did not significantly differ before and after 40 weeks $(\mathrm{P}=0.2$ and 0.3 , respectively). Among the 22170 births $\geq 40$ weeks' gestation, there were seven deaths out of 10602 births in hospitals with $<3000$ births a year and one death out of 11568 births in hospitals with $\geq 3000$ births a year $(\mathrm{P}=0.02)$.

Of the 12633 women who had previously given birth vaginally, $1499(11.8 \%)$ were induced with prostaglandin compared with 2976 of the 20215 (12.8\%) women who had not done so $(\mathrm{P}=0.006)$. We used a logistic regression model to estimate the absolute risk of uterine rupture (including cases in which the infant survived and cases in which the infant died) in relation to different combinations of parity and induction of labour with prostaglandin in relation to 1998 rates. Among women who had not previously given birth vaginally, the risk of uterine rupture without induction of labour with prostaglandin was one in 210 and with induction of labour with prostaglandin was one in 71. Among women with a previous vaginal birth, the risk of uterine rupture without induction of labour with prostaglandin was one in 514 and with induction of labour with prostaglandin was one in 175 .

\section{Discussion}

We found that after a previous caesarean section women who had not previously given birth vaginally and those who had labour induced with prostaglandin were at increased risk of uterine rupture. The same two factors were associated with the risk of perinatal death due to uterine rupture. In contrast, delivering in a hospital with low throughput was not associated with uterine rupture overall but was associated with an increased risk of perinatal death due to uterine rupture. We found that uterine rupture was three times more likely to result in death of the infant if the delivery took place in a hospital with $<3000$ births a year. Confining trials of labour to larger obstetric units may therefore reduce the risk of perinatal death associated with uterine rupture during a trial of labour.

The finding that units with high throughput had lower rates of perinatal death due to uterine rupture is plausible. Hospitals with greater throughput are more likely to have resident obstetric, anaesthetic, and neonatal services as well as a dedicated obstetric operating theatre. These factors would allow a faster response to fetal distress due to uterine rupture, which in turn would allow more rapid delivery and resuscitation of the neonate. We did not have information on the structure of services at each unit over the period of study. However, the factors are likely to be highly correlated and interdependent. A

Table 2 Univariate obstetric associations with uterine rupture and perinatal death due to uterine rupture. Figures are numbers (percentages) unless stated otherwise

\begin{tabular}{|c|c|c|c|c|c|c|c|c|}
\hline \multirow[b]{2}{*}{ Characteristics } & \multicolumn{4}{|c|}{ Uterine rupture } & \multicolumn{4}{|c|}{ Perinatal death due to uterine rupture } \\
\hline & Yes $(n=124)$ & No $(n=35730)$ & $\begin{array}{l}\text { Relative risk (95\% } \\
\text { CI) }\end{array}$ & $P$ value* & Yes $(n=17)$ & Not $(n=35$ 837) & $\begin{array}{l}\text { Relative risk (95\% } \\
\text { Cl) }\end{array}$ & $P$ value* \\
\hline$<3000$ births a year & $63(50.8)$ & $16930(47.4)$ & 1.1 (0.8 to 1.6$)$ & 0.47 & $13(76.5)$ & 16980 (47.4) & 3.6 (1.2 to 11.1$)$ & 0.03 \\
\hline No previous vaginal birth & $102(82.3)$ & $23089(64.6)$ & 2.5 (1.6 to 4.0$)$ & $<0.0001$ & $15(88.2)$ & $23176(64.7)$ & $4.1(0.9$ to 17.9$)$ & 0.04 \\
\hline $\begin{array}{l}\text { Induction of labour } \\
\text { without prostaglandin } \neq\end{array}$ & $13(10.5)$ & $4416(12.4)$ & 1.1 (0.6 to 2.0$)$ & 0.75 & $2(11.8)$ & $4427(12.4)$ & 1.2 (0.3 to 5.6$)$ & 0.68 \\
\hline $\begin{array}{l}\text { Induction of labour with } \\
\text { prostaglandin } \neq\end{array}$ & $39(31.4)$ & $4436(12.4)$ & 3.3 (2.2 to 4.8$)$ & $<0.0001$ & $5(29.4)$ & $4470(12.5)$ & 3.0 (1.0 to 8.8$)$ & 0.05 \\
\hline Gestation $>41$ weeks & $8(6.4)$ & $1867 \quad(5.2)$ & $1.2(0.6$ to 2.6$)$ & 0.54 & $0(0.0)$ & $1875(5.2)$ & - & $>0.9$ \\
\hline
\end{tabular}

*Fisher's exact test (two sided).

tIncludes 35730 women who did not have uterine rupture documented and 107 women who had uterine rupture documented but it did not result in stillbirth or neonatal death

łSame reference category for both: all women in whom labour was not induced. 
Table 3 Multivariate analysis (with odds ratios and 95\% confidence intervals) of risk of uterine rupture and perinatal death due to uterine rupture

\begin{tabular}{|c|c|c|c|c|}
\hline \multirow[b]{2}{*}{ Characteristics } & \multicolumn{2}{|c|}{ All uterine rupture } & \multicolumn{2}{|c|}{ Perinatal death due to uterine rupture } \\
\hline & Adjusted OR $(95 \% \mathrm{Cl})^{\star} \dagger$ & $P$ value & Adjusted OR $(95 \% \mathrm{Cl})^{*}$ & $P$ value \\
\hline$<3000$ births a year & $1.1(0.8$ to 1.5$)$ & 0.67 & $3.4(1.0$ to 14.3$)$ & 0.04 \\
\hline No previous vaginal birth & 2.5 (1.6 to 3.9$)$ & $<0.001$ & 4.1 (0.9 to 36.6$)$ & 0.06 \\
\hline Induction of labour with prostaglandin & $2.9(2.0$ to 4.3$)$ & $<0.001$ & $2.5(0.7$ to 7.7$)$ & 0.17 \\
\hline
\end{tabular}

*Adjusted for each of other factors.

†Also adjusted for year of delivery.

unit with no resident obstetric or anaesthetic cover is unlikely to have a dedicated obstetric operating theatre or a resident experienced neonatologist. Therefore, even if these data were available, it would be extremely difficult to determine the independent contributions of each of these factors in reducing the risk of death. Therefore, the total number of births is a useful composite measure of the level of support and has the pragmatic advantage of being easy to define.

\section{Study strengths and weaknesses}

Previous large scale analyses of the factors determining uterine rupture could not reliably distinguish between asymptomatic dehiscence of the previous caesarean section scar and clinically significant, symptomatic uterine rupture. ${ }^{189}$ The failure to define the event may lead to ascertainment bias. As asymptomatic dehiscence of the scar will generally be identified during a subsequent caesarean section, there will be increased ascertainment of uterine rupture for any exposure that is associated with an increased risk of caesarean delivery. As we were able to study perinatal death due to uterine rupture, this allowed us to identify catastrophic rupture that would be ascertained irrespective of the mode of delivery. We conclude that the associations between uterine rupture and no previous vaginal birth and induction of labour with prostaglandin are unlikely to be explained by ascertainment bias. Previous studies have suggested that the protective effect of a previous vaginal birth is observed whether it preceded or followed the first caesarean delivery. ${ }^{10}$

\section{Findings are comparable with previous studies}

The estimates of absolute risk in the present analysis are comparable with those from previous studies. The overall rate of successful vaginal delivery of $74.2 \%$ is similar to the generally quoted overall figure of $75 \% .{ }^{11}$ The overall rate of uterine rupture of $0.35 \%$ is consistent with that reported in a previous large scale Swiss study. ${ }^{9}$ The overall risk of perinatal death due to uterine rupture (one in 2100) is similar to the one in 2600 reported in a study from Washington State, USA. ${ }^{1}$ The risk among large obstetric units (one per 4700) is similar to a case series from a large obstetric centre in California (one per 4200). ${ }^{12}$ Although the total number of perinatal deaths in our study was relatively small (17), this is almost three times more than reported in a recent meta-analysis of all previous studies. ${ }^{13}$ Guise et al commented that the risk of death in Scotland, as cited from our previous report, ${ }^{2}$ was 10 times higher than reported in other studies. ${ }^{13}$ However, the figure they quoted was for perinatal death due to all causes related to delivery. The absolute risk of death due to uterine rupture in our previous study (4.5 per 10000$)$ was similar to the overall risk in our current analysis. Both fall within the $95 \%$ confidence intervals of the meta-analysis. We believe that the current data give the best estimate of the absolute risk of perinatal death among women attempting vaginal birth after caesarean.

A previous population based study had shown an association between induction of labour with prostaglandin and uterine rupture. ${ }^{1}$ This finding led the American College of Obstetricians and Gynecologists to recommend avoidance of prostaglandin in women with a previous caesarean section. However, the number of women was small (366) and this was less than $2 \%$ of the study population. In the present study, we had data on 4475 women who had labour induced with prostaglandin, which was $12.5 \%$ of our cohort. Our analyses confirmed that induction of labour with prostaglandin, but not other methods, was independently associated with an increased risk of uterine rupture, including catastrophic rupture leading to perinatal death. It remains to be determined whether this is due to a specific pharmacological effect or whether the use of prostaglandin is merely a marker for a woman with an unfavourable cervix.

We defined trial of labour as any woman who had a single previous caesarean birth who was delivered at term by a means other than planned caesarean section. The cohort studied probably includes some women who were due for planned repeat caesarean section but attended in early labour, had an emergency caesarean delivery, and did not truly attempt vaginal birth. However, women delivering at or after 40 weeks are unlikely to have requested planned repeat caesarean section. We found that the nature and strength of associations in the present study were similar when we confined analyses to births at or after 40 weeks' gestation, and misclassification of attempted vaginal birth is unlikely to have significantly affected our results.

\section{Conclusion}

In summary, we have shown that the risk of uterine rupture is increased among women who have not previously given birth vaginally and those undergoing induction of labour with prostaglandin. Our data show that the risk of consequent death of the infant is lower in obstetric units with higher throughput. Although other interpretations could be made, we believe the most plausible explanation for these findings is that the facilities generally available at larger obstetric units reduce the risk of

Table 4 Factors associated with perinatal death among women with documented uterine rupture. Figures are numbers (percentages) unless stated otherwise

\begin{tabular}{|c|c|c|c|c|c|c|}
\hline Characteristics & $\begin{array}{l}\text { Uterine rupture led to } \\
\text { perinatal death }(n=17)\end{array}$ & $\begin{array}{l}\text { Uterine rupture did not lead to } \\
\text { perinatal death }(n=107)\end{array}$ & Relative risk $(95 \% \mathrm{Cl})$ & P value ${ }^{*}$ & $\begin{array}{l}\text { †Adjusted odds ratio (95\% } \\
\text { CI) }\end{array}$ & $P$ value \\
\hline$<3000$ births a year & $13(76.5)$ & $50(46.7)$ & 3.1 (1.1 to 9.1$)$ & 0.03 & $3.9 \neq(1.2$ to 12.8$)$ & 0.03 \\
\hline No previous vaginal birth & $15(88.2)$ & $87(81.3)$ & $1.6(0.4$ to 6.6$)$ & 0.73 & 1.7 (0.4 to 8.3) & 0.79 \\
\hline $\begin{array}{l}\text { Induction of labour with } \\
\text { prostaglandin } †\end{array}$ & $5(29.4)$ & $34(31.8)$ & 0.9 (0.3 to 2.4) & $>0.9$ & 0.8 (0.2 to 2.6) & 0.85 \\
\hline
\end{tabular}

†From exact logistic regression.

†Univariate odds ratio=3.7. Higher value of adjusted odds ratios compared with relative risk is due to relatively high incidence of event in group. 


\section{What is already known on this topic}

Attempting vaginal birth after previous caesarean section (VBAC) carried the risk of uterine rupture, which may result in perinatal death

No studies to date have examined the factors associated with perinatal death due to uterine rupture during attempted VBAC

No studies to date have examined the organisation of health care and the risk of perinatal death due to uterine rupture during attempted VBAC

\section{What this study adds}

For women attempting VBAC, no previous vaginal birth and induction of labour with prostaglandin were associated with uterine rupture resulting in perinatal death

The risk of perinatal death due to uterine rupture was greater in hospitals with lower annual numbers of deliveries

perinatal death in the event of uterine rupture. The same is probably true of other obstetric emergencies. Perinatal deaths could, therefore, potentially be reduced by confining high risk births to large obstetric units or by providing additional facilities at smaller units.

Contributors: GCSS had the original idea. DP reviewed previous publications. GCSS and DP undertook the statistical analyses and wrote the initial draft. RD performed the record linkage. GCSS, JPP, and DP agreed the study design, interpreted the results, and revised the original draft. All authors approved the final version. GCSS is the guarantor.

Funding: None.

Competing interests: None declared.

Ethical approval: Not required.
1 Lydon-Rochelle M, Holt VL, Easterling TR, Martin DP. Risk of uterine rupture during labor among women with a prior cesarean delivery. N Engl J Med 2001;345:3-8.

2 Smith GCS, Pell JP, Cameron AD, Dobbie R. Risk of perinatal death associated with labor after previous cesarean delivery in uncomplicated term pregnancies. JAMA 2002;287:2684-90.

3 Cole SK. Scottish maternity and neonatal records. In: Chalmers I, Mcllwaine GM, eds. Perinatal audit and surveillance. London: Royal College of Obstetricians and Gynaecologists, 1980:39-51.

4 Mcllwaine GM, Dunn FH, Howat RC, Smalls M, Wyllie MM, MacNaughton MC. A routine system for monitoring perinatal deaths in Scotland. Br J Obstet Gynaecol 1985;92:913.

5 Hey EN, Lloyd DJ, Wigglesworth JS. Classifying perinatal death: fetal and neonatal factors. Br J Obstet Gynaecol 1986;93:1213-23.

6 Hosmer DW, Lemeshow S. Applied logistic regression. New York: John Wiley, 2000.

7 Oster RA. An examination of statistical software packages for categorical data analysis using exact methods. Am Stat 2002;56:235-46.

8 Gregory KD, Korst LM, Cane P, Platt LD, Kahn K. Vaginal birth after cesarean and uterine rupture rates in California. Obstet Gynecol 1999;94:985-9.

9 Rageth JC, Juzi C, Grossenbacher H. Delivery after previous cesarean: a risk evaluation. Swiss Working Group of Obstetric and Gynecologic Institutions. Obstet Gynecol Swiss Working

10 Zelop CM, Shipp TD, Repke JT, Cohen A, Lieberman E. Effect of previous vaginal delivery on the risk of uterine rupture during a subsequent trial of labor. Am J Obstet Gynecol 2000;183:1184-6.

11 Flamm BL. Vaginal birth after caesarean (VBAC). Best Pract Res Clin Obstet Gynaecol 2001;15:81-92.

12 Miller DA, Diaz FG, Paul RH. Vaginal birth after cesarean: a 10-year experience. Obstet Gynecol 1994;84:255-8.

13 Guise J-M, McDonagh MS, Osterweil P, Nygren P, Chan BKS, Helfand M. Systematic review of the incidence and consequences of uterine rupture in women with previous caesarean section. BMJ 2004;329:19-23.

(Accepted 3 June 2004)

doi $10.1136 /$ bmj.38160.634352.55

Department of Obstetrics and Gynaecology, Cambridge University, Cambridge CB2 2QQ

Gordon C S Smith professor

Department of Public Health, Greater Glasgow NHS Board, Glasgow G3 8YU Jill P Pell consultant

Departments of Obstetrics and Gynaecology, Addenbrooke's NHS Trust,

Cambridge CB2 2SW

Dharmintra Pasupathy specialist registrar

Information and Statistics Division, Common Services Agency, Edinburgh EH5 3SE

Richard Dobbie senior statistician

Correspondence to: G C S Smith gcss2@cam.ac.uk 